\title{
NMR crystallography of 2D and 3D assemblies of functional molecules
}

\author{
M. Dračínský, G. Bastien, C. Santos-Hurtado, J. Michl, J. Kaleta \\ Institute of Organic Chemistry and Biochemistry, Czech Academy of Sciences, Flemingovo nám. 2, Prague, Czech Republic \\ dracinsky@uochb.cas.cz
}

Artificial molecular machines promise applications in many fields, including physics, information technologies, chemistry as well as medicine. The deposition of functional molecules in $2 \mathrm{D}$ or $3 \mathrm{D}$ assemblies in order to control their collective behavior and the structural characterization of these assemblies are challenging tasks. We exploit porous materials to form rigid matrix for mechanochemical preparation of bulk or surface host-guest inclusions with functional molecules, such as molecular rotors, molecular motors and molecular switches.

Unambiguous determination of the molecular structure and monitoring of the molecular function such as rotation of a molecular rotor or on/off switching of a molecular switch cannot be studied by X-ray analysis because the systems are typically heavily disordered fine powders. We use solid-state nuclear magnetic resonance (SS-NMR) spectroscopy to obtain atomic-level insights into the structure and dynamics of these functional materials. SS-NMR spectra provide valuable information about structure, interactions and dynamics in solids not available otherwise.

It will be demonstrated that SS-NMR experiments provide unequivocal evidence of the formation of the 2D and 3D assemblies and can also be used for the observation of such a molecular function as the photoisomerization of a molecular switch deposited on a surface. We have also developed a solid-state NMR method for investigation of two dimensional arrays of light-driven molecular motors [1-4].

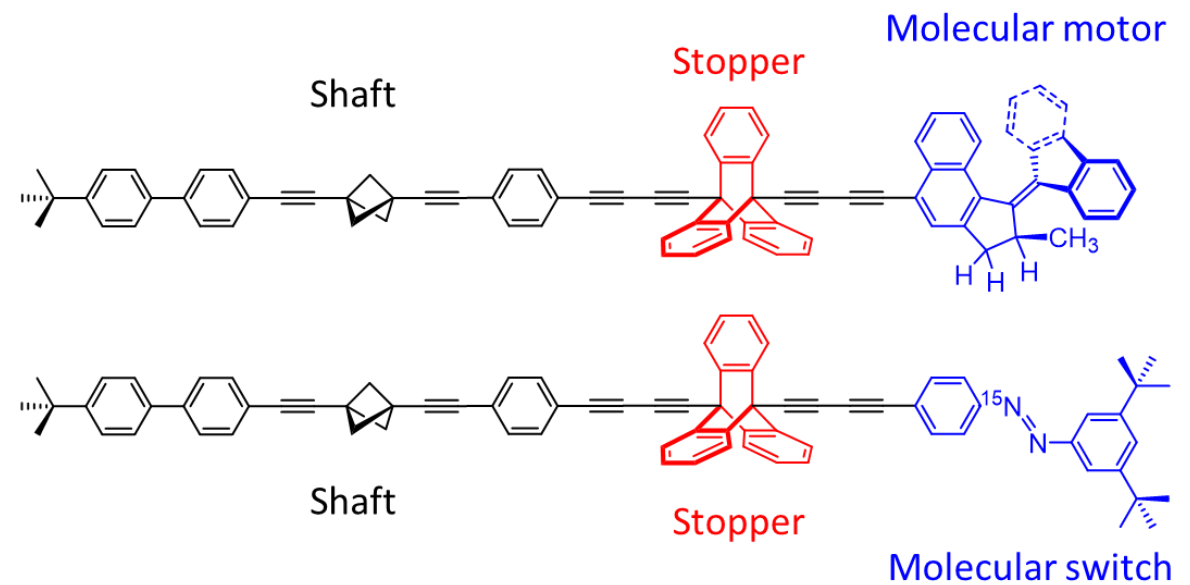

Figure 1. Examples of studied molecules. The shaft ensures deposition of the molecules in the porous molecular matrix, the stopper ensures surface deposition. The molecular motor is a unidirectional light-driven motor and the switch performs its function upon UV irradiation.

[1] Kaleta, J., Chen, J., Bastien, G., Dračínský, M., Mašát, M., Rogers, C. T., Feringa, B. L., Michl, J. (2017). J. Am. Chem. Soc. 139, 10486.

[2] Kaleta, J., Bastien, G., Wen, J., Dračínský, M., Tortorici, E., Císařová, I., Beale, P. D., Rogers, C. T., Michl, J. (2019). J. Org. Chem. 84, 8449.

[3] Santos-Hurtado, C., Bastien, G., Mašát, M., Štoček, J. R., Dračínský, M., Rončević, I., Císařová, I., Rogers, C., Kaleta, J. (2020). J. Am. Chem. Soc. 142, 9337.

[4] Dračínský, M., Santos-Hurtado, C., Masson, E., Kaleta, J. (2021). Chem. Commun. 57, 2132.

\section{Keywords: NMR crystallography; molecular machines; photoswitching}

The work was supported by Czech Science Foundation (grant no. 20-01472S). 